\title{
Modifikasi Model Edukasi di Masa Pandemi untuk Menjaga Ketaatan Diet dan Minum Obat Pasien Diabetes Melitus
}

\author{
Joko Sudarsono*, Budiyanti Wiboworini, Yulia Lanti Retno Dewi, Dwi Rahayu, Amelya Augusthina \\ Ayusari, Widardo, Kusmadewi Eka Damayanti, Risalina Myrtha, Sutartinah Sri Handayani dan Kisrini
}

Program Studi Pendidikan Dokter, Fakultas Kedokteran, Universitas Sebelas Maret, Surakarta, Indonesia

Diterima: 24 Februari 2021; Disetujui: 10 April 2021

\begin{abstract}
Abstrak
Palang Merah Indonesia (PMI) sebagai mitra memiliki klinik untuk penderita penyakit kronis dan sebelum pandemi COVID 19 telah melakukan kegiatan pemeriksaan dan edukasi secara rutin. Penyakit yang banyak diderita salah satunya adalah diabetes melitus, dengan permasalahan utama yaitu konsumsi makanan belum terjadwal dengan baik dan ketidakteraturan minum obat. Masa pandemi menyebabkan kegiatan di klinik terhenti, sehingga perlu diberikan modifikasi cara edukasi untuk menjaga agar pasien tetap dapat mengikuti dietnya dengan baik. Pasien perlu terus mendapat edukasi karena penyakit diabetes merupakan penyakit yang sulit disembuhkan tetapi dapat dikendalikan dengan ketaatan diet dan minum obat. Agar edukasi dapat dilakukan tanpa tatap muka, maka dilakukan upaya edukasi berbasis digital. Kegiatan pengabdian dilakukan melalui tahapan identifikasi masalah mitra; pengambilan data pasien atau keluarga pasien yang memiliki nomor WhatsApp (WA), pembuatan script dilanjutkan pembuatan video, penyebaran video melalui Google Drive dan youtube serta diakhiri dengan sesi diskusi di kelas WA. Materi pengabdian meliputi edukasi dalam menyusun menu dan mengatur asupan makronutrien, serta edukasi masyarakat dalam kegiatan minum obat. Perubahan pengetahuan diukur dari hasil pretest dan posttest terkait materi. Antusiasme peserta dapat dilihat dari banyaknya pertanyaan sepanjang sesi diskusi kelas WA. Hasil pengabdian menunjukkan peningkatan pengetahuan terhadap penyusunan menu yang baik guna mencukupi kebutuhan baik makronutrien maupun mikronutrien serta pengetahuan tentang penggunaan obat diabetes yang benar sebesar $20 \%$. Hasil ini menunjukkan penggunaan video dan edukasi digital melalui WA dapat menjadi alternatif sebagai media edukasi pasien di masa pandemi.
\end{abstract}

Kata kunci: diabetes melitus; edukasi digital; konsumsi makanan; obat

\section{Modification of Education Models during Pandemic to Keep Medicine and Diet Compliance for Diabetes Mellitus Patients}

\section{Abstract}

Indonesian Red Cross (PMI) as a partner has a clinic for patients with chronic diseases with regular inspections and education. Diabetes mellitus is one of the most common disease in PMI clinic, with main problems are diet style and medicine compliance. The pandemic has caused the clinic activities stopped; so it is necessary to modify the patients' educational methods. Limitations in face-to-face education during pandemic, could be overcome by digital-based education. Community service activities were carried out through the identification of partner problems; collecting data on patients

\footnotetext{
* Corresponding author: jokosudarsono@staff.uns.ac.id

Cite this as: Sudarsono, J., Wiboworini, B., Dewi, Y. L. R., Rahayu, D., Ayusari, A. A., Widardo, Damayanti, K. E., Myrtha, R., Handayani, S. S., \& Kisrini. (2021). Modifikasi Model Edukasi di Masa Pandemi untuk Menjaga Ketaatan Diet dan Minum Obat Pasien Diabetes Melitus. AgriHealth: Journal of Agri-food, Nutrition and Public Health, 2(1), 17-22. doi: http://dx.doi.org/10.20961/agrihealth.v2i1.48804
} 
or patients' families with WhatsApp numbers, making scripts followed by making videos; distributing the video via Google Drive and Youtube and ended with a discussion session via WhatsApp group. The education contents include menus preparation and managing macronutrient intake and public education in medicine compliance. Changes in knowledge was measured from the results of the pretest and posttest related to the material. The results showed an increase in knowledge of good menu preparation to meet the needs of both macronutrients and micronutrients as well as knowledge of the correct use of diabetes drugs by 20\%. These results indicated that the use of video and digital education through WhatsApp group can be an alternative of patients education during pandemic.

Keywords: diabetes mellitus; digital education; drug; food intake

\section{PENDAHULUAN}

Pengabdian ini awalnya direncanakan dilakukan di Klinik Palang Merah Indonesia (PMI) Cabang Surakarta sebagai mitra, yang telah memberikan persetujuan. Selama ini kegiatan yang sudah dilakukan di klinik mitra meliputi senam, edukasi, pemeriksaan gula darah sewaktu dan pemeriksaan lab lain secara berkala. Program ini sudah berjalan hampir 5 tahun, dengan anggota prolanis 48 orang dengan penderita diabetes melitus (DM) sebanyak 22 orang dan sisanya menderita penyakit kronis lainnya seperti hipertensi. Berdasar penelusuran data awal terdapat beberapa permasalahan mitra terkait DM, yaitu konsumsi makanan belum terjadwal dengan baik, sering bingung memilih dan mengatur menu yang tepat, serta kebanyakan penderita DM tidak mengkonsumsi obat secara teratur dengan berbagai alasan. Masa pandemi menjadikan kegiatan klinik terhenti, sehingga edukasi dan konseling yang merupakan bagian penting dari terapi DM tidak bisa dilaksanakan. Kondisi ini penting untuk dicarikan solusi, mengingat DM merupakan penyakit kronis yang prevalensinya terus meningkat dan sulit disembuhkan. Pada penderita DM, diet dan konsumsi obat yang tidak teratur berpotensi meningkatkan risiko komplikasi kronis yang menurunkan kualitas hidup dan bahkan bisa fatal (Rosyada dan Trihandini, 2013).

World Health Organization (WHO) memprediksikan penderita DM akan menjadi sekitar 366 juta orang pada tahun 2030. Penyumbang peningkatan angka tadi merupakan negara-negara berkembang, yang mengalami kenaikan penderita DM $150 \%$ yaitu negara penderita DM terbanyak adalah India (35,5 juta orang), Cina (23,8 juta orang), Amerika Serikat (16 juta orang), Rusia (9,7 juta orang) dan Jepang (6,7 juta orang) (WHO, 2016). Berdasarkan hasil
Survei Riset Kesehatan Dasar prevalensi DM di Indonesia dari tahun 2018 sebesar 8,5\% (Kemenkes, 2018).

Diabetes Melitus (DM) adalah suatu kelainan metabolik pada seseorang, ditandai naiknya kadar glukosa dalam darah (hiperglikemia) yang diakibatkan kekurangan insulin dan sering disertai tanda/ gejala lain trias poli: poliuria, polidipsia dan polifagia (Care, 2015). Menurut Hajian-Tilaki dan Heidari (2015); Pongsatha et al. (2012), kesalahan dalam pola makan dapat menyebabkan terjadinya obesitas dan kelebihan berat badan yang masalah tersebut berhubungan dengan peningkatan risiko kejadian DM. Diet merupakan terapi dasar pada penderita DM, tetapi sebagian besar pasien DM tidak mengikuti diet yang dianjurkan dengan mengurangi kalori. Kondisi pasien yang tidak patuh menjalankan terapi diet menyebabkan level gula darah tidak terkendali. Penelitian membuktikan, seorang pasien DM yang patuh menjalani diet secara rutin dan pengukuran level gula darah terkendali, bisa mengurangi kejadian komplikasi jangka pendek maupun jangka panjang serta komplikasi makro dan mikro vaskular (Almatsier, 2015). Faktor kepatuhan terhadap pengobatan perlu diperhatikan disamping faktor pengaturan diet, gaya hidup dan olahraga (Almaini dan Heriyanto, 2019). Edukasi bagaimana minum obat juga perlu dilakukan karena sekitar $50 \%$ orang DM tidak patuh minum obat (Adikusuma dan Qiyaam, 2017).

Sehubungan kondisi pandemi, kegiatan Prolanis di klinik mitra tidak berjalan sebagaimana mestinya hingga akhir Juni 2020 dan tidak ada kepastian kapan akan mulai berjalan. Edukasi dan sekaligus monitoring ketaatan diet serta minum obat tidak dapat dilakukan, maka tim pengabdian melakukan modifikasi kegiatan. Mengingat komunikasi 
paling mudah dilakukan secara daring, maka dilakukan modifikasi untuk memberikan edukasi dalam bentuk video. Tim pengabdian juga menambahkan penderita DM yang berdomisili di wilayah Surakarta, Sukoharjo dan Boyolali yang merupakan bagian dari wilayah Eks Karesidenan Surakarta. Wawancara awal dengan sub sampel menunjukkan masalah yang sama dengan masalah yang dialami pasien DM di Prolanis PMI, yakni kesulitan dalam mengatur diet dan sulitnya mematuhi jadwal minum obat secara teratur. Perilaku tidak taat ini dapat juga disebabkan ketidaktahuan, sehingga melalui video edukasi yang disebarkan kepada para pasien DM dan atau keluarganya, diharapkan dapat meningkatkan pengetahuan pasien atau keluarga yang merawat mengenai diet dan cara minum obat yang benar bagi pasien DM. Kegiatan pengabdian dilaksanakan dengan target luaran meningkatnya pemahaman peserta serta tersosialisasinya video edukasi ini kepada masyarakat khususnya penerapan edukasi pada masyarakat penderita DM tentang pentingnya menjaga asupan makanan terutama makronutrien, berat badan dan kepatuhan minum obat untuk meningkatkan kualitas hidupnya.

\section{BAHAN DAN METODE}

Pengabdian ini dilakukan secara daring menggunakan video dan WhatsApp Group, dengan peserta dari klinik PMI sebagai mitra ditambah penderita DM yang berdomisili di wilayah Surakarta, Sukoharjo dan Boyolali. Total peserta sejumlah 76 orang yang memiliki riwayat atau terdiagnosis DM, atau keluarga yang merawat penderita DM. Secara keseluruhan, kegiatan ini memakan waktu kurang lebih 3 bulan, karena diperlukan banyak persiapan sebelum pelaksanaan kelas WhatsApp sebagai forum diskusi. berikut:

Rincian langkah-langkah pelaksanaan sebagai

1. Penyusunan materi pengabdian dan pembuatan script video.

Materi edukasi sesuai dengan rencana awal, yakni mengenai pengaturan makan dan kepatuhan minum obat bagi penderita DM. Pemilihan materi ini juga didasarkan atas survei awal pada sub sampel yang telah mengumpulkan data serta wawancara pada 3 orang pengelola Prolanis yang menunjukkan masih perlunya kedua materi tersebut diberikan. Selanjutnya disusun script video.

2. Pembuatan model video edukasi untuk diulas bersama.

Hasil ulasan menunjukkan perlunya pemisahan topik pengaturan makan dengan kepatuhan minum obat menjadi dua video agar tidak terlalu panjang. Pada tahap ini juga dilakukan revisi script dan shooting ulang.

3. Editing video yang diserahkan pada profesional

4. Unggah video ke Google Drive dan youtube.

5. Pendataan sasaran edukasi untuk membentuk kelas WA (Gambar 1).

6. Melakukan pretest dan membagikan link youtube video edukasi dan penyampaian video edukasi di kelas WA untuk dipelajari lebih dahulu.

7. Membuka sesi diskusi dan tanya jawab terkait isi video edukasi selama 2 jam pada hari Sabtu, tanggal 17 Oktober 2020 jam 10.00 sampai dengan jam 12.26.

8. Pada akhir acara dilakukan posttest untuk mengevaluasi hasil pelaksanaan edukasi tersebut. Pretest dan posttest diberikan melalui tautan Google Form.

\section{HASIL DAN PEMBAHASAN}

Kegiatan pengabdian ini telah menghasilkan dua buah video edukasi berisi materi pengabdian. Video edukasi pengaturan makan (Gambar 2) telah diunggah pada Youtube dengan tautan: https://www.youtube.com/watch?v=W_QYzO -Ingk\&t=1s, sedangkan video tentang edukasi kepatuhan minum obat (Gambar 3) diunggah pada tautan berikut: https://www.youtube.com/ watch?v=k7YvvibALJw.

Sesi diskusi diadakan melalui kelas WA selama 2 jam setelah pasien melihat video yang disiapkan. Peserta mengikuti dengan antusias terbukti dengan sesi tanya jawab yang berlangsung secara interaktif. Sebelum diskusi diadakan pretest dan dicek ulang pengetahuan yang didapat dengan posttest menggunakan 15 soal yang sama. Sayangnya dari 76 peserta hanya 36 peserta yang mengerjakan pretest dan posttest karena mayoritas adalah pasien berusia lanjut sehingga kesulitan dalam menggunakan Google Form. Jumlah jawaban benar pretest terendah adalah 3 dan tertinggi adalah 15, sedangkan jumlah jawaban benar posttest terendah adalah 9 dan tertinggi adalah 15 . 


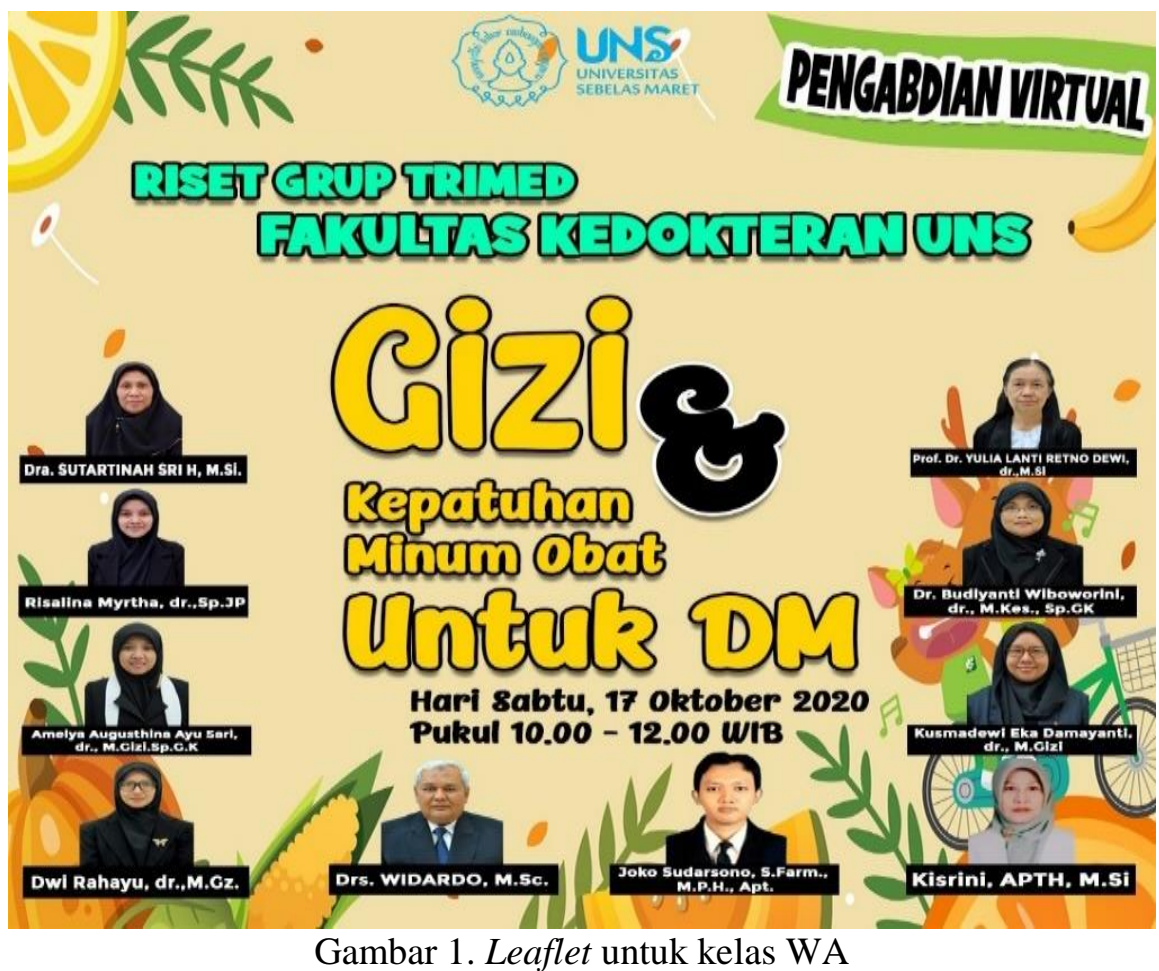

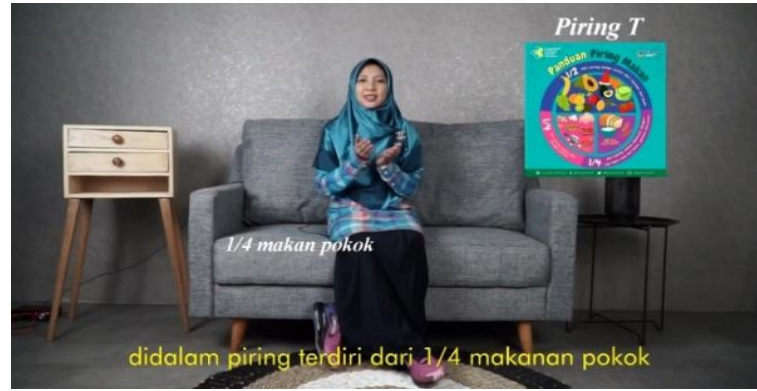

Gambar 2. Penyampaian materi video edukasi pengaturan makan

Berdasarkan hasil pretest dan posttest (Gambar 4) didapatkan peningkatan nilai posttest bila dibandingkan dengan pretest. Peningkatan nilai pretest dibanding posttest rata-rata sebesar 3 poin atau sekitar $20 \%$. Penggunaan media video dan juga penggunaan aplikasi chat dalam memberikan edukasi cukup efektif dalam kondisi pandemi. Masyarakat tetap mendapatkan informasi tentang kesehatan yang terbatas oleh jarak dan tempat secara khusus tentang penyusunan menu makanan dan penggunaan obat bagi penderita DM. Efektivitas edukasi melalui video di youtube juga terlihat dari jumlah pemirsa youtube yang sudah melebihi 2 kali jumlah peserta kelas edukasi WA.

Pertanyaan yang muncul saat diskusi mengindikasikan bahwa pasien atau keluarga pasien seringkali menemukan situasi yang

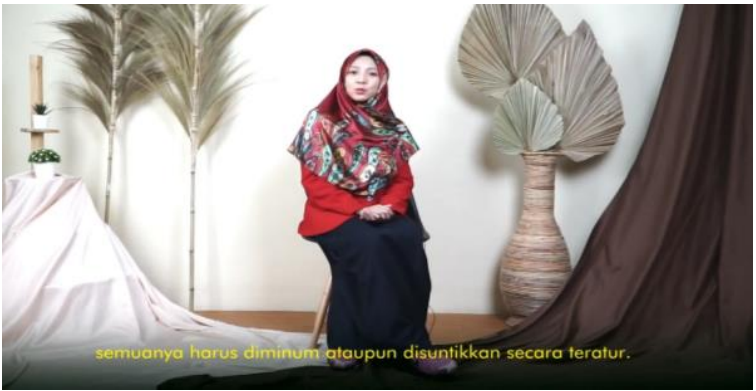

Gambar 3. Penyampaian materi video edukasi kepatuhan minum obat

memerlukan penjelasan lebih lanjut dari tenaga kesehatan. Contohnya adalah peserta yang menanyakan boleh tidaknya konsumsi madu pada pasien DM, juga pertanyaan tentang efek samping obat penurun gula yang digunakan. Hal ini menunjukkan bahwa pasien DM perlu untuk terus diedukasi untuk mengantisipasi situasi yang muncul sejalan dengan perkembangan penyakitnya. Penelitian Hengky dan Haniarti (2018) dan Febrianti et al. (2020) menunjukkan perlunya terus dilakukan edukasi pada pasien DM terkait pola makannya karena masih banyak pasien DM yang tergolong tidak baik pola makannya dari sisi jumlah maupun frekuensi makan. Melalui kelas edukasi dan penyebaran video edukasi pasien DM dan masyarakat umum bisa mendapatkan informasi yang dibutuhkan tersebut. 


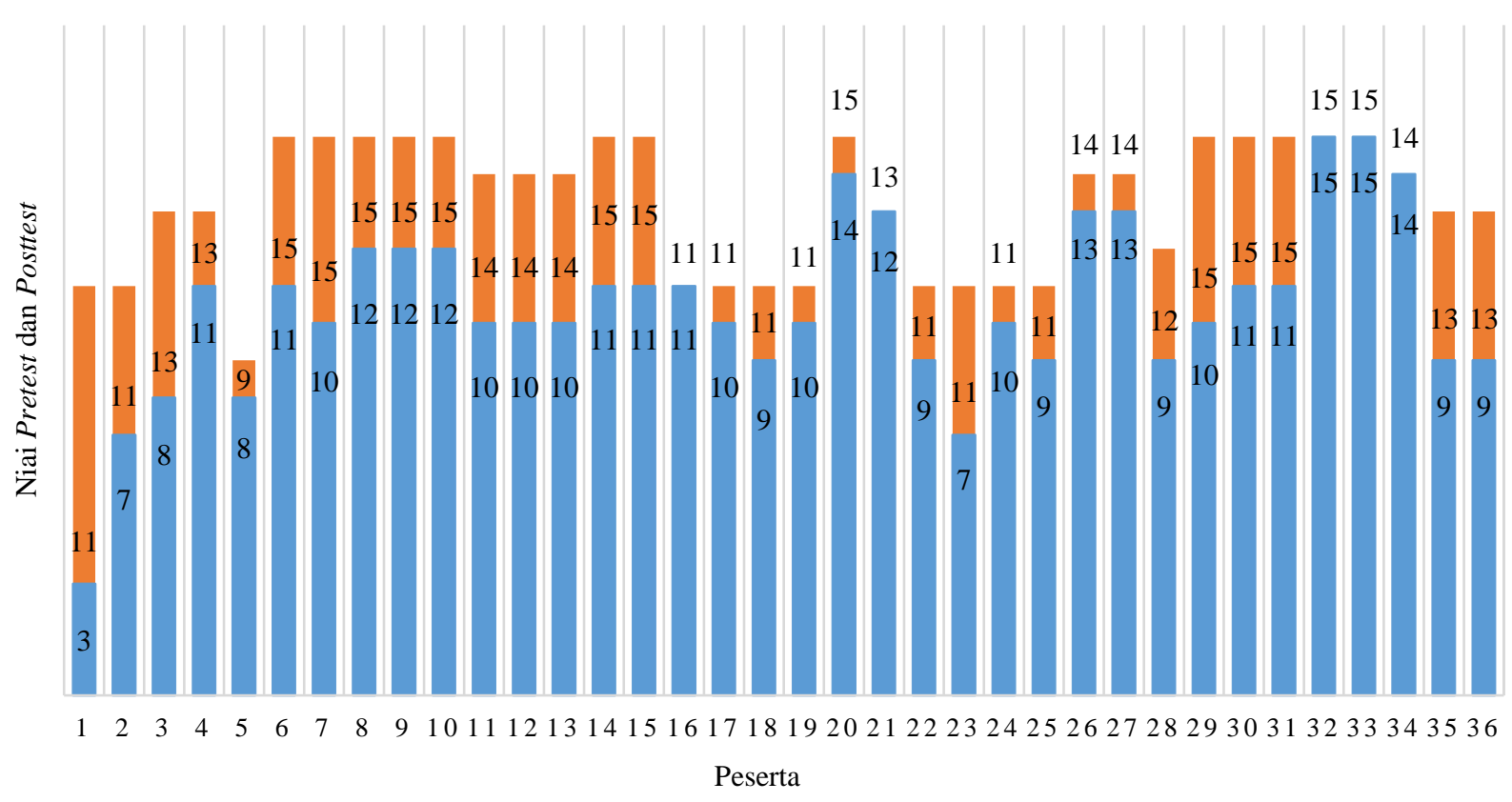

Gambar 4. Grafik hasil pretest dan posttest

\section{KESIMPULAN}

Edukasi secara digital melalui video dan diskusi interaktif di kelas WA dapat meningkatkan pengetahuan peserta dalam hal pengaturan diet dan ketaatan minum obat pasien DM. Penggunaan media video dan forum WA Group dapat menjadi alternatif untuk penyuluhan atau edukasi masyarakat yang efektif.

\section{UCAPAN TERIMA KASIH}

Pengabdian ini didanai dengan hibah HRG UNS dengan nomor Kontrak 453/UN27.21/ $\mathrm{PN} / 2020$.

\section{DAFTAR PUSTAKA}

Adikusuma, W., \& Qiyaam, N. (2017). Hubungan tingkat kepatuhan minum obat antidiabetik oral terhadap kadar hemoglobin terglikasi (HbA1c) pada pasien diabetes melitus tipe 2. Jurnal Ilmiah Ibnu Sina, 2(2), 279-286. Tersedia dari http://e-jurnal.stikes-isfi.ac.id/ index.php/JIIS/article/view/105

Almaini, A., \& Heriyanto, H. (2019). Pengaruh kepatuhan diet, aktivitas fisik dan pengobatan dengan perubahan kadar gula darah pada pasien diabetes mellitus Suku Rejang. Jurnal Keperawatan Raflesia, 1(1), 55-66. https:// doi.org/10.33088/jkr.v1i1.393
Almatsier, S. (2015). Prinsip dasar ilmu gizi. Jakarta: Gramedia Pustaka Utama.

Care, F. (2015). Standards of medical care in diabetes. Introduction. Diabetes Care, 38, S1S2. https://doi.org/10.2337/dc15-S001

Febrianti, D., Thaha, R. M., \& Hidayanty, H. (2020). Pola makan pasien rawat jalan dm tipe 2 di Rumah Sakit Pendidikan UNHAS. Jurnal Kesehatan Masyarakat Maritim, 3(1), 44-56. https://doi.org/10.30597/jkmm.v3i1.10284

Hajian-Tilaki, K., \& Heidari, B. (2015). Is waist circumference a better predictor of diabetes than body mass index or waist-to-height ratio in Iranian adults? International Journal of Preventive Medicine, 6(1), 12-17. https:// doi.org/10.4103/2008-7802.151434

Hengky, H. K., Mardhatillah, N., \& Haniarti. (2018). Hubungan pola makan dengan insidensi diabetes melitus tipe 2 pada wanita usia dewasa di RSUD Andi Makksau Kota Parepare. Jurnal Ilmiah Manusia dan Kesehatan, 1(1), 34-41. Tersedia dari http://jurnal.umpar.ac.id/index.php/makes/arti cle/view/100

Kemenkes. (2018). Hasil utama Riset Kesehatan Dasar (Riskesdas) 2018. Badan Penelitian dan Pengembangan Kesehatan, Kementerian Kesehatan. Tersedia dari https://www.litbang. kemkes.go.id/hasil-utama-riskesdas-2018/ 
Pongsatha, S., Morakot, N., Sangchun, K., \& Chaovisitsaree, S. (2012). Correlation between waist circumference and other factors in menopausal women in Thailand. Health, 4(2), 60-65. https://doi.org/10.4236/ health.2012.42011

Rosyada, A., \& Trihandini, I. (2013). Determinan komplikasi kronik diabetes melitus pada lanjut usia. Kesmas: Jurnal Kesehatan Masyarakat Nasional (National Public Health Journal), 7(9), 395-401. http://dx.doi.org/ 10.21109/kesmas.v7i9.11

WHO. (2016). Global report on diabetes. Paris: World Health Organization. Tersedia dari https://www.who.int/publications/i/item/9789 241565257 